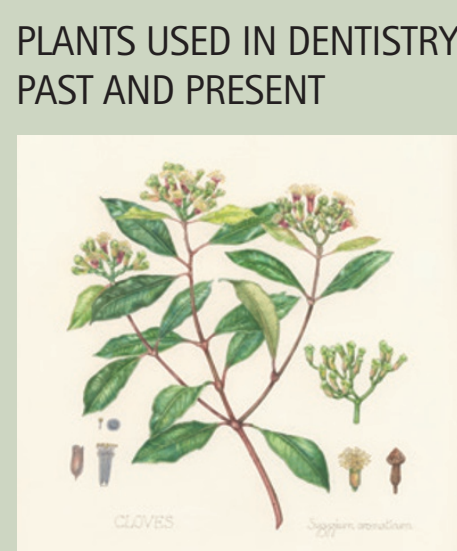

This issue of the $B D J$ displays the first cover in a brand new series. The theme for Volume 218 is 'Plants and trees in dentistry's past and present'.

The first cover, for issue 1 , is an original illustration of cloves, created by artist Liz Pepperell. Liz is creating all 12 covers in the style of traditional botanical drawings.

Cloves are the aromatic flower buds of a tree in the Myrtaceae family, Syzygium aromaticum. In the past cloves were used as a remedy to ease the pain of toothache. Clove oil has a local anaesthetic effect and temporarily numbs and relieves pain. It is used in the preparation of some toothpastes and in Clovacaine solution, a local anaesthetic used in oral ulceration and inflammation. Eugenol, which is extracted from essential oils including clove oil, is also mixed with zinc oxide to form temporary tooth restorations.

Artist Liz Pepperell lives in Devon and loves visiting gardens such as Nymans in West Sussex and Knightshayes Court in Devon, which inspire the plants and flowers that she paints. She works in watercolours, pencil and ink, in a style traditional in the world of botanical and natural history illustration.

When approaching an illustration, Liz first sketches loose ideas in pencil and ink on tracing paper, scrubbing out and redrawing as she goes. Whenever possible she works from life.

Future covers in Volume 218 will feature original illustrations of licorice root, miswak, myrrh, neem tree and tea tree.

\section{FROM THE ARCHIVE}

\section{BLOOD AND THUNDER DENTISTRY}

$\mathrm{R}$ etired dentist Alan G. Green contacted the $B D J$ having seen the special 'From the archive' featuring 97-year-old Sydney Grennan (Grubs, fire bombs, India and a paper in the British Dental Journal; BDJ 2014; 217: 216-217).

Captain Alan G. Green LDS RADC published the article $A$ survey of the dental condition of 19-yearold youths in the BDJ on 21 April 1953 in Volume 94 (pictured). The survey examined 500 youths called up for service with the Army and selected as potential vehicle drivers. The following text is an extract from the article, under the heading 'DISCUSSION':

It would seem that the dental condition of those surveyed is most unsatisfactory and that many had not received treatment through lack of initiative, understanding, or opportunity.

There is overall a dislike of dentures which is part based on parental experience.

An average DMF index of 8 has been obtained. [...] It is strongly felt that the group possessed little, if any, understanding of matters dental, and it is hoped that more is now being done in the schools to emphasise that pain is not the only criterion of the necessity for dental treatment. Very much the same opinion was formed by Palmer (1950) who studied statistically dental conditions in New York. He stated that "Most patients do not visit the dentist unless they are in pain, have a swollen face or a broken tooth."

A frequent reason given for the refusal of dental treatment was "I had some fillings done some time ago, but they fell out soon after - so I don't believe in them."

Alan also sent the $B D J$ an account of his student, hospital and army days which we are pleased to share with readers, as follows:

Tlived in Liverpool throughout the war and was accustomed to the bomb damage. In 1945, at the tender age of 17, I became a naive dental student. With so much housing stock destroyed, student accommodation was in very short supply and living at home, commuting to uni, was the order of the day. Kids living around the university were often shoeless. There was a different definition of poverty!

The quad was covered by a pile of coal, Liverpool's emergency supply for homes and ships. Dissection in winter was a problem as the dissecting room's windows had been blown out and not replaced. Hats, overcoats and any warm clothing was the order of the day. The male toilet had a large container for urine, donations requested by Biochemistry. Unfortunately, a stirrup pump [used for tackling incendiary bomb fires] was located nearby so a visit to the 'loo' was extremely hazardous. We were fortunate to have an early

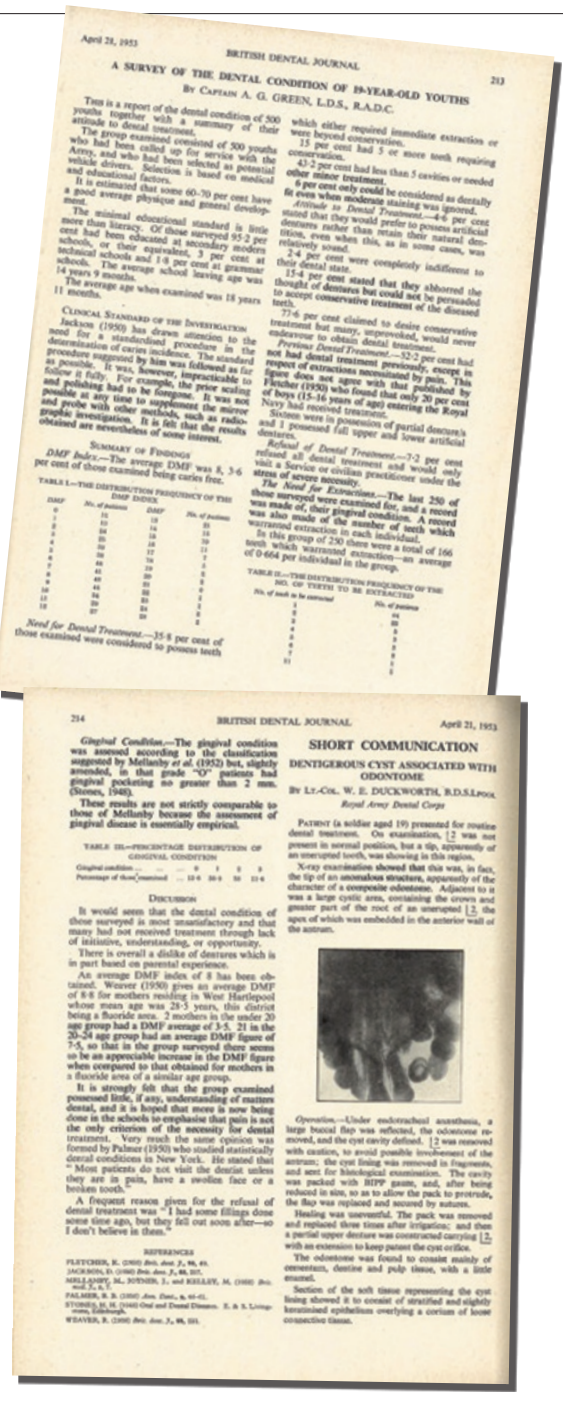

supply of the miracle LA, xylocaine, but antibiotics were not available and trench mouth prevalent at the time was treated by the archaic chromic acid and hydrogen peroxide method. 'Cons' had one functioning hot water steriliser which never reached boiling due to the frequent instrument exchanges. For the first six months we had to use foot engines. I was never sure whether it was worse for the patients or the student operator. In prosthetics 'compo' was used for some impressions. It went from patient to lab and back to another patient. Surprisingly, we never noticed cross infection problems!

The class of 1945 were mostly from school but the class of " 46 was very different. The ex-servicemen were those with the longest war service, veterans of bombing raids, the Battle of the Atlantic and every aspect of the war. One baby-faced, apparent school leaver turned out to be a retired major whose last posting had been the Inspector of Brothels in Cairo. We had an eclectic student mix! 
1948 saw the opening of the NHS. The hospital was besieged by patients needing new, free-of-charge dentures. So many patients claimed to have lost their old ones whilst being seasick on the ferry across the Mersey that it was a wonder that there was any water left for the ferries to sail on. One old guy wanted a set to suit himself and his wife. He claimed they had shared the same dentures all their married life and he saw no reason to change.

‘Cons' was run by Frank Lawton, later Professor Sir Frank Lawton. He had exacting standards and we were not short of restorative work. My wife and I first met in the conservation department as she was a 'finals' patient of my best friend.

I was most surprised to find that I had passed my finals and to be offered a house surgeon's post. In those days the university staff could be counted in single numbers. Fulltime hospital staff amounted to one registrar and five junior house officers. Unfortunately, one of our number developed meningitis and so we were rapidly reduced to four. I was directed to 'extractions' and within a few weeks of qualification I was teaching extractions and, in the absence of a visiting anaesthetist, teaching anaesthesia as well. An 'extreme' vocational training. We had many full mouth clearances, both permanent and deciduous, and each morning's session would have more than 20 GAs and over 100 teeth extracted. The use of an Oxford Inhaler and Vinesthine for children was particularly brutal. It was truly 'blood and thunder dentistry'.

In due course I found myself called up for National Service. Presented with an opportunity I recorded the dental state and attitudes of army recruits. It makes unpleasant reading but is not surprising given my previous student experiences.

Later I was posted to Austria where my first patient turned out to be a soldier who had refused treatment to me several weeks earlier back in the UK. When asked why he had refused he said 'it was because he was a bloody awful dentist, sir'. [I'd been unable to offer him GA for an extraction.] I was responsible for the dental departments of the hospitals in Graz and Vienna. The equipment and materials were 'experienced' having been captured from the German Army during their retreat through Italy. I had to commute through the Russian zone. At Semmering the Russians would put an armed guard around the train whilst troops checked all occupants. There were no illegal immigrants into the Russian Zone! This was a time of heightened tension and a great deal of intelligence activity. I had many interesting patients, not least the Czech pilot who arrived in a stolen MIG fighter! He had bridgework the like of which I had neither seen before nor have seen since.

If the 'balloon went up' my task was to drive a troop-carrying vehicle with my DSA riding shotgun at the rear of the convoy evacuating families, picking up and treating casualties as we went along. Fortunately, this was only conducted as an exercise.

I was lucky in that my wife had been able to come with me for a holiday visit which lasted for the whole of my posting. She was not allowed to work as a physiotherapist but was recruited to present Sunday's Family favourites on the Forces' radio. Technology was not then available to extend Jean Metcalfe's two-way family favourites between Germany and UK to Austria. It was a fantastic experience marred by the thought that National Service (NS) Dental Officers were being exploited. As a Captain my pay was £32 per month. The army charged £27 per month for my wife's accommodation and so we had just $£ 5$ uncommitted. These were special arrangements for medical and dental officers. There was no way that other NS officers could afford to bring out their wives.

Back in the UK we still had rationing, utility clothing and furniture. In Austria there was food and clothing of a quality and quantity that was beyond our experience. It seemed that we had won the war but lost the peace.

\section{'I had many interesting patients, not least the Czech pilot who arrived in a stolen MIG fighter! He had bridgework the like of which I had neither seen before nor have seen since.'}

The time came when we had to return to UK. A military train ran between the railhead at Klagenfurt and the Hook of Holland. There was no room on the train for my wife and so we just managed to scrape enough money together to buy her a Forces' ticket from Vienna on BEA. When I arrived at Klagenfurt I was told that I was Officer in charge of the train! I had to sign for 16 or more coaches. Shortly into the journey a wagon ran a hot axle and we had to abandon it. At Badgastein we were stopped and informed that a signalman had reported that a grenade had been thrown from the train at his signalbox. We were to arrest the individual and send him back under escort. I was very relieved when we finally arrived at the Hook and I was able to hand over what was left of the train without having to pay for the missing coach.

Back in the UK I decided to 'squat' a practice in Liverpool. NHS fees were very depressed and taxes were high - but that is another story.

\section{BDA BRANCH AGMS}

\section{Essex}

Essex Branch AGM will be held on 2 February 2015 at $6.30 \mathrm{pm}$ in Chelmsford Golf Club, Widford, Chelmsford. North Essex Section AGM will be held on 4 February 2015 at $6.45 \mathrm{pm}$ in the Holiday Inn, Eight Ash Green, Colchester. To confirm attendance or submit apologies for either event, contact Nick Barker via email: nickbarker@tiscali.co.uk

West Lancs/West Cheshire/ North Wales

West Lancs/West Cheshire/ North Wales Branch AGM will be held on 10 February 2015 at 6 pm; light refreshments from $5.30 \mathrm{pm}$ at Clatterbridge Hospital Postgraduate Centre, Bebington, Wirral. For further information or to confirm attendance/submit apologies please contact the Branch secretary Linda Dunlop on ldunlop76@aol.com.

\section{DO DENTURES IMPROVE QUALITY OF LIFE?}

Research from the University of Adelaide's Australian Research Center for Population Oral Health challenges current thinking on whether many people with tooth loss really need dentures.

Studies have found that people with tooth loss do not have their quality of life interfered with provided they still have a certain number and type of teeth left.

These patients are considered to have shortened dental arches, enabling them to maintain functional use of many teeth. The researchers say there is a cutting off point at which tooth loss interferes with quality of life, but patients only need dentures when they reach that cutting off point.

The study, based on data of more than 2,700 Australians, is to be published in a future issue of Community Dentistry and Oral Epidemiology. The researchers say as many as 434,000 Australians who currently would be considered for dentures at some stage in their lives may not really need them. 